\title{
The effects of risk on initial trust formation
}

\author{
Svein Tvedt Johansen ${ }^{1}$, Marcus Selart², Kjell Grønhaug ${ }^{2}$ \\ 'Department of Business Administration and Social Sciences, Harstad University College \\ ${ }^{2}$ Department of Strategy and Management, NHH Norwegian School of Economics
}

\begin{abstract}
Correspondence concerning this article should be addressed to Svein Tvedt Johansen, Department of Business Administration and Social Sciences, Harstad University College, N9480 Harstad, Norway.

E-mail: svein.johansen@hih.no
\end{abstract}

doi: 10.1111/jasp.12082

\begin{abstract}
This paper seeks to expand our understanding of initial trust by looking at how variation in risk influences the nature of trust and the process of initial trust formation. Four hypotheses were tested in two experiments involving participants with and without work experience. A first hypothesis suggested a positive relationship between a general propensity to trust and initial trust; a second hypothesis, a negative relationship between risk and initial trust; whereas a third hypothesis posited that risk would increase the importance participants place on benevolence and integrity. A fourth hypothesis suggested that risk would have a positive and moderating influence on the effect of out-of-role behavior when presented after roleconformant in-role behavior. Findings are presented and discussed and practical implications suggested.
\end{abstract}

\section{Introduction}

How does initial trust form between individuals in organizations? Understanding initial trust formation is important for two reasons: First, even long-term relationships begin with initial trust and initial trust tends to shape subsequent interaction through its effects on expectations (Vlaar, Van den Bosch \& Volberda, 2007). Second, initial trust situations, situations where people meet and need to interact with and cooperate with new and unknown individuals, have become more prevalent as a result of increased reliance on temporary work groups (Saunders \& Ahuja, 2006), restructuring (Falkenberg, Stensaker, Meyer, \& Haueng, 2005), and increased use of external consultants (McKenna, 2006). Some of these relationships never develop beyond a short term relationship.

Trust is defined here as the "willingness of a party to be vulnerable to the actions of another party based on the expectation that the other will perform a particular action important to the trustor, irrespective of the ability to monitor or control that other party" (Mayer, Davis, \& Schoorman, 1995, p. 713). Trust may be based on a trustor's evaluation of the trustee's ability, benevolence, integrity, and most usually a combination of the three (Kramer, 1999; Mayer et al., 1995). Ability can be defined as "that group of skills, competencies and characteristics that enable a party to have influence within some specific domain" (Mayer et al., 1995, p. 717). Benevolence is "... the extent to which a trustee is believed to want to do good to the trustor, aside from an egocentric profit motive" (Mayer et al., 1995, p. 718). Integrity is that "... a trustee adheres to a set of principles that the trustor finds acceptable" (Mayer et al., 1995, p. 719). Trust between different situations is likely to differ in their emphasis on ability, benevolence, and integrity. Trust in some situations may be about ability, whereas trust in other situations may be about benevolence and integrity (Kramer, 1996). Initial trust here refers to trust in the initial stages of a relationship where the parties have no or little experience with the other (McKnight \& Chervany, 2006; McKnight, Cummings, \& Chervany, 1998).

Experimental findings as well as case studies suggest that people do trust and manage to work with people they have little or no prior knowledge about (Meyerson, Weick, \& Kramer, 1996; Orbell \& Dawes, 1991; Ostrom, 2003; Weber, Malhotra, \& Murnighan, 2005). Several contributions as a result has sought to explain how initial trust forms. McKnight et al. (1998) thus see initial trust as based on a combination of dispositional, cognitive, and institutional factors. McKnight et al. (1998) argue that initial trust is enabled by a person's disposition to trust, including his or her faith in humanity and stance toward trusting strangers (Rotter, 1967). Initial trust is also made possible by a trustor's beliefs that the necessary institutional structures (e.g., contracts, courts) are in place to protect one's interests (Giddens, 1991; Lane, 1998) and by the trustor's experience that a situation is normal and intelligible (Garfinkel, 1963; Zucker, 1986). Finally, McKnight et al. suggest that initial trust is facilitated by categorization 
processes that enable a trustor to import assumptions based on the trustee's unit membership (e.g., belonging to the same organization; Williams, 2001) or profession (Barber, 1983). Meyerson et al. (1996) likewise described initial or swift trust in temporary work groups as enabled by reliable professional role performance, reputation effects, or people guarding their reputation within a limited pool of contractors, as well as the reputation of the contractor. Both contributions see initial trust as being based on a perception of the trustee being reliable, predictable, and able. Thus, initial trust in these contributions resembles what Lewicki and Bunker (1996) refer to as calculative trust and McAllister (1995) as cognitive-based trust.

These contributions offer valuable insight on initial trust formation. Yet, they also have multiple problems: Their focus is on describing antecedents to initial trust to explain a phenomenon; initial trust. The contributions however fail to explain when people are likely to attend to different information sources. The models explain, but do not predict.

While initial trust is differentiated from trust produced in established relationships, contributions on initial trust has little to say about the effects of the trustor's situation on initial trust and initial trust formation (McKnight \& Chervany, 2006). While risk is not discussed extensively, the emphasis on reliability, predictability, and ability in these descriptions resemble the trust characteristic of the initial low-risk, low-commitment interactions (Lewicki \& Bunker, 1996). Thus, risk in the initial stages is assumed to be moderate to low.

This assumes that relationships start with small to moderate levels of risk and that risk results from people's discretionary choices. People initially abstain from committing themselves to a relationship and gradually raise their investments in the relationships as they gain experience with the trustee (Lewicki \& Bunker, 1996). Risk and dependence however is often ingrained in the structure of the situation irrespective of a trustor's choices. People thus often find themselves depending on people they may not even know, and people's knowledge of that relationship is likely to influence the initial interaction (Selart, 2010).

We define risk here as "... the extent to which there is uncertainty about whether potentially significant and/or disappointing outcomes of decisions will be realized" (Sitkin \& Pablo, 1992, p. 10). Risk has three dimensions: outcome uncertainty or the variability of outcomes; lack of knowledge of the distribution of potential outcomes; and the uncontrollability of the outcome potential (Sitkin \& Pablo, 1992). Outcome expectations refer to the expected outcomes of a decision or action. Outcome potential refers to the possible range of outcomes as represented in questions like "How bad could it get" or "How much could I win." We will concern ourselves with variation in the negative outcome potential, as expressed in "how bad could it get."
Studies of romantic as well as professional relationships suggest that the nature and type of dependence between a trustor and a trustee influence the nature of trust or what trust is about. Thus hierarchical position (at the bottom or at the top) influences the importance a trustor place on benevolence or ability (Kramer, 1996). Different relationships similarly tend to emphasize different dimensions depending on the degree of dependence (Fiske, 1992; Sheppard \& Sherman, 1998). Generalizing from this, we suggest that risk is likely to vary even within initial trust situations and that this variation is likely to influence what trust is about. As a result, existing contributions on initial trust formation by not including variation in risk, is likely to restrict our understanding of initial trust and initial trust formation. Descriptions of initial trust formation in situations involving low to moderate levels of risk may not generalize to high-risk situations. Here, we seek to expand our understanding of initial trust formation by exploring the effects that variation in risk has on the content of trust, or what trust is about and related to this, how initial trust forms.

In studying the process of initial trust formation, we will be interested in the effects of in-role vs. out-of-role behavior on initial trust. In-role behavior here refers to the behavior expected of a professional role incumbent, whereas out-ofrole behavior refers to behavior that is not associated with or expected from a role incumbent (Guiot, 1977). Initial trust is often viewed as facilitated by a reliable professional inrole behavior (Barber, 1983; Meyerson et al., 1996). Thus, Meyerson et al. (1996) posit that role-based interaction “... leads to more rapid development of trust than does personbased interaction" (181). Inconsistent role behavior on the other hand raises questions about the reliability of the trustee and slows the development of trust (Meyerson et al., 1996). Other contributions however suggest that sanctioned behavior (in-role behavior) is less informative about the true intentions of a trustee and hence less influential for eliciting trust (Luhmann, 1979). According to Luhmann “... roleconformity offers little opportunity for the presentation of self. Anyone who merely conforms will not be seen as self at all, and therefore can be trusted as little as the person who hurries past" (Luhmann, 1979).

In the rest of the paper, we proceed by developing four hypotheses: A first hypothesis posits a positive relationship between a general propensity to trust and initial trust. The second hypothesis proposes a negative direct relationship between risk and initial trust. A third hypothesis states that risk will influence the content of trust, increasing the importance trustors attach to a trustee's benevolence and integrity and finally, a fourth hypothesis states that risk will influence the effect of out-of-role behavior where out-of-role behavior follows after in-role behavior. The next section then introduces two experiments involving two different samples, and presents findings and null findings from the experiments. 


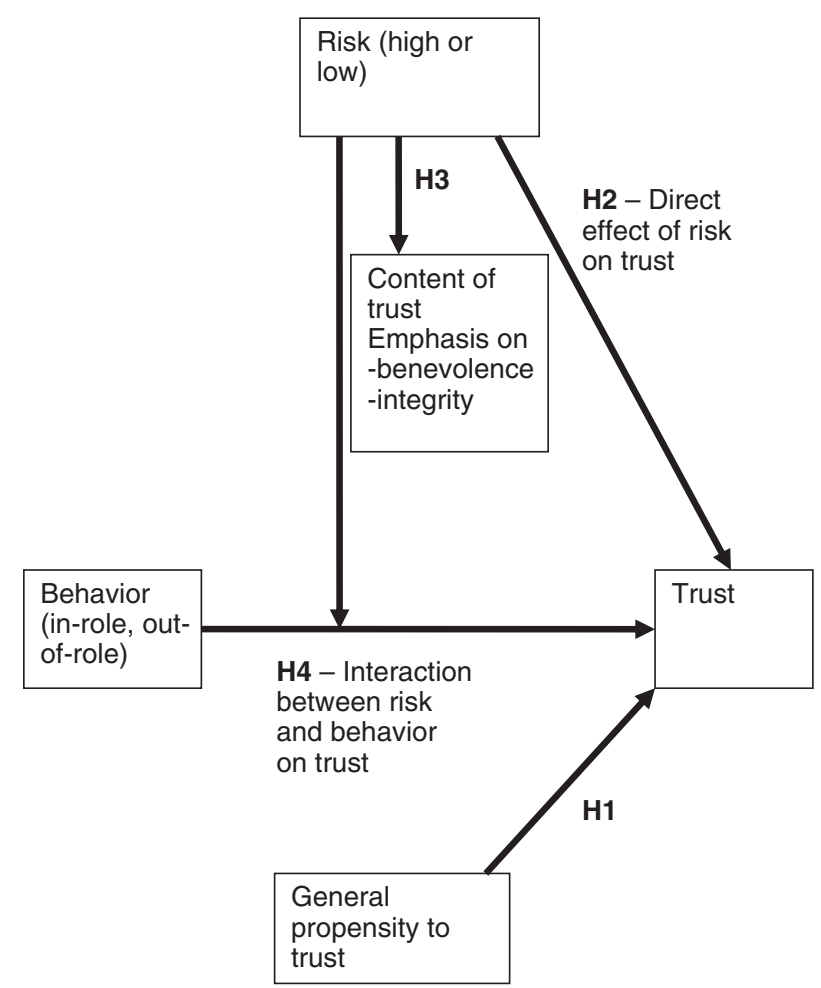

Figure 1 Research model.

Finally, the last section includes a discussion of findings and no findings, limitations, as well as practical implications. Figure 1 shows the research model.

\section{Hypotheses}

Trust has long been linked to a general propensity to trust or a general, stable, within-person factor that influences willingness to trust others across situations and contexts (Mayer et al., 1995; Rotter, 1967, 1971). A propensity to trust is based on early trust-related experiences. People's extrapolations from these early experiences develop into general beliefs about other people that eventually take the form of a trait or personality characteristic (Erikson, 1968; Rotter, 1971).

Empirical findings however have failed to find a strong and convincing general relationship between a general propensity to trust and trust (Johnson-George \& Swap, 1982). Several contributors as a result have suggested a contingent relationship in which a general propensity to trust influence trust in situations where people have little or no specific information at hands. Where people have access to more specific information through experience or secondary information, people rely on this information (Gill, Boies, Finegan, \& McNally, 2005).

Mayer et al. (1995) thus suggest that a trustor's propensity to trust will influence a trustor's trust in a trustee, in the initial stages of a relationship, before the trustor has attained any information on the trustee. In the absence of more concrete data about the trustee, people fill in with more general expectations. Later, as a trustor gain more specific information about the trustee, general expectations becomes less important. A slightly different yet related argument is provided by Gill et al. (2005) who relates the influence of a general propensity to trust on the strength of the situation (Gill et al., 2005; Mischel, 1977): Weak situations are characterized by having “. . . highly ambiguous behavioral cues that provide few constraints on behavior, and do not induce uniform expectations" (Gill et al., 2005, p. 293). Strong situations on the other hand have ". . . salient behavioral cues that lead everyone to interpret the circumstances similarly, and induce uniform expectations regarding the appropriate response" (Gill et al., 2005, p. 293). In well-defined strong situations, Gill et al. suggest, propensity to trust is likely to be overwhelmed by the situation and the specific experiences of the trustor. Initial trust situations provide trustors with little information about a trustee and normally imply weak situations with ambiguous cues and unclear expectations.

Hypothesis 1. Propensity to trust will show a positive relationship with initial trust.

The relationship between risk and trust has been conceived of in different ways. First, some see a direct correspondence between perceived risk and subjective trust: According to Das and Teng (2004), "subjective trust refers to assessed probabilities of having performed desirable action by the trustee," whereas perceived risk is "the assessed probabilities of not having desirable results" (98-99). Thus, perceived risk and subjective trust can be seen as inverse properties. High subjective risk equals low trust, whereas low subjective risk equals high trust (Das \& Teng, 2004).

Mayer et al. (1995) on the other hand see risk as a situational feature that moderate the relationship between trust and risk taking in relationship. In their model, perceived risk is described as "a trustor's beliefs about gains or losses outside of the relationship with a particular trustee” (1995, p. 726). The trustor compares the level of trust with the level of risk. Where the level of trust surpasses the level of perceived risk, people will engage in risk taking in relationships. Where the level of perceived risk surpasses the level of trust, people abstain from risk taking in relationship. Risk in this model does not influence trust as a willingness to be vulnerable, but ultimately influence behavior.

We still believe however that risk is likely to reduce trust for several reasons.

A first reason reflects the way trust is measured. Mayer et al. define trust as a trustor's willingness to engage in risk taking and measure trust accordingly as a trustor's willingness to engage in risk taking in relationships. The consequences of engaging in the sort of risk taking in relationship captured in 
the trust scale (a representative item from the trust scale is "I would be comfortable giving the consultant a task or problem which was critical for me, even if I could not monitor their action") are likely to be greater for vulnerable trustors (who stand a high chance of actually losing their job).

Second, risk is likely to activate the behavioral inhibition system (Macleod \& Mathews, 1988), increasing people's sensitivity to threats and punishments (MacLeod \& Mathews, 1988). The behavioral inhibition system further causes people to perceive threats in ambiguous stimuli and situations (MacLeod \& Mathews, 1988). A general effect of the behavioral inhibition system is to inhibit behavior that could cause negative or painful outcomes and inhibit movements toward goals. As a result, risk, by activating the behavioral inhibition, is likely to reduce trust by sensitizing people to threats and aversive outcomes and inhibit goal-strivings. Risk is also likely to activate a predecisional, deliberative mindset (Gollwitzer, Heckhausen, \& Steller, 1990; Taylor \& Gollwitzer, 1995). A predecisional, deliberative mindset implies a prevention focus in which people seek to avoid negative outcomes as opposed to approach positive outcomes (Higgins, 1997; Higgins, Idson, Freitas, Spiegel, \& Molden, 2003) and is associated with deliberative, effortful, and controlled information processing (Erber \& Fiske, 1984; Gollwitzer et al., 1990; Neuberg \& Fiske, 1987). People in a deliberative mind state pay greater attention to unexpected, incongruous, and potentially individuating information (Erber \& Fiske, 1984), thus increasing the likelihood that a trustor will find negative or disconcerting information about a trustee. A deliberate mindset also has other consequences that are likely to undermine trust: Thus, a deliberative mindset reduces or eliminates the illusion of control biases, which otherwise characterizes a post-decisional, implemental mindset and leads to worsened mood states, as well as increasing people's perception of risk (Taylor \& Gollwitzer, 1995).

Hypothesis 2. There will be a negative relationship between risk and initial trust.

Risk influences not only the level of trust but even what trust is about. People in different circumstances are likely to attach different importance to ability, benevolence, and integrity (Mayer et al., 1995). Different social situations present people with different opportunities and different threats and imply the relevance of specific needs and motives (Holmes, 2002; Kelley et al., 2002; Rusbult \& Van Lange, 2003). The structure of social situations can be described in terms of level of dependence or the degree to which an individual's outcomes are influenced by his or her interaction partner's actions (Kelley et al., 2002). Mutuality of dependence is the extent to which two individuals are equally dependent on each other (mutual dependence) or one partner is comparatively more reliant on the other (nonmutual dependence). Covariation of interests describes the extent to which an outcome that ben- efits one interaction partner also benefits the other. Perfectly, correspondent situations imply that outcomes that benefit one partner also benefit the other. Mixed-motive situations imply some common and some conflicting interests. Finally, some situations may have perfectly conflicting outcomes in which one partner's gain is the other partner's loss (Holmes, 2002; Kelley \& Thibaut, 1978; Rusbult \& Van Lange, 2003).

Different situations afford or allow for the expression of different traits. Situations characterized by high, nonmutual dependence, and conflicting interests afford the expression of prosocial motives, responsiveness, benevolence, integrity, as well as the opposite, narrow, self-serving behavior (Holmes, 2002). In contrast, situations characterized by low to moderate, mutual dependence, and nonconflicting interests (both partners seek the same outcome) afford the expression of reliability and ability but not benevolence.

Risk is likely to change the structural properties of a situation.

Risk in the form of a negative outcome potential (e.g., losing a job) is likely to influence the relationship to an interaction partner, particularly where this person is viewed as being able to influence the outcome or possess what is commonly referred to as fate control. More specifically, risk is likely to increase nonmutual dependence and accentuate conflicting interests (as one partner must attend to the interests of the organization and the other worries about her job). Risk as a result, we suggest, will increase a trustor's concern with the responsiveness, benevolence, and integrity of the trustee. In accordance with this, Kramer (1996) shows how doctoral students (highly dependent on their professors) were concerned with their professors' care or benevolence, whereas professors (less dependent on their doctoral students) were more focused on doctoral students' reliability or ability. Similarly, Rempel, Holmes, and Zanna (1985) find that high dependence in romantic relationships trigger questions about responsiveness. Sheppard and Sherman (1998), building on Fiske's work on relationship schemas (Fiske, 1992), show how the nature of dependence (shallow vs. deep dependence) raises attention to different dimensions of trustworthiness. Thus relationships characterized by deep dependence (e.g., authority ranking) introduces the risks of cheating, abuse, neglect, or threats to self-esteem and evokes a concern with a trustee's (e.g., the boss) integrity, concern, or benevolence.

Hypothesis 3. Greater risk will be associated with a greater emphasis on benevolence and integrity.

The content of trust or what trust is about we argue, influence how initial trust forms and more specifically the effect of social information (in-role vs. out-of-role behavior) on initial trust. People seek to reduce uncertainty with respect to the dimensions that mitigate for the salient risks that people face in a specific situation (Sheppard \& Sherman, 1998). In situations where the prime concern is with the trustee's 
competence, people seek to discern information about the ability of the trustee, whereas in other situations where people confide their innermost secrets, the trustees' integrity and willingness to keep their word of not spreading that information is likely to be central.

Here, we suggest that peoples' exposure to risk and their vulnerability in the situation is likely to influence peoples' responses to in-role vs. out-of-role behavior. Hypothesis 2 posits that risk will increase the importance trustors attach to benevolence and integrity.

Ability is consistent with the consultant role and readily discernible through a trustee's in-role behavior. A consultant has incentives for performing well and no interests in concealing his or her ability. Enacting the role of a consultant may in itself convey an impression of ability based on assumptions of stringent selection criteria (Gambetta, 1988). In contrast, benevolence and integrity relates to a trustee's intentions and choices in situations that involve trade-offs and conflicting interests, as well as weak situations that provide few constraints on behavior (Mischel, 1977). Benevolence and integrity is defined by how a trustee behave when it is not in the trustee's interest to respond to some ones' need or abide to a moral code. Sanctioned and constrained in-role behavior provides few cues as of the true intentions of the trustee. Out-of-role or role-incongruent behavior, or behavior that goes against expectations and role expectations, is likely to be much more revealing about the true intentions and hence about the benevolence and integrity of the trustee (Ajzen, 1971; Gilbert, 1998; Jones, Davis, \& Gergen, 1961).

Brief exposure to a trustee is unlikely to provide a trustor with definitive answers about the trustee's trustworthiness. Still, we posit that even brief episodes can inform initial trust. Kramer (1994) thus found that merely ruminating about someone's motives and intentions increased an individual's confidence in the accuracy of his or her judgment about another person. In a similar vein, Davis and Kotteman (1994) found that merely watching someone led people to overinflate confidence in their own judgment. People moreover are likely to be sensitive to the extent of which information help further their informational goals, that is, provide information about someone's ability or intentions (benevolence and integrity). In a series of experiments, Ferguson and Bargh (2004) found that participants actively engaged in goal pursuit compared to participants not engaged in goal pursuit, evaluated goal-relevant objects more favorably than goalirrelevant objects. Extending on this, goal-relevant information should also be evaluated more favorably than goal-irrelevant information. Finally, in a different set of experiments, Dunn and Schweitzer (2005) demonstrate how incidental emotions influence trust in unrelated settings. Positive emotions including happiness and gratitude increase trust, whereas anger decreases trust. The influence of incidental emotions on trust that the authors find is limited to situa- tions where the trustor is unaware of the source of their emotions as well as situations where the trustor is not too familiar with the trustee.

We suggest that a positive effect of out-of-role behavior will manifest itself only where this out-of-role behavior follows after role-congruent in-role behavior. Two arguments support this claim. First, Sheppard and Sherman (1998) argue that risks in relationships are cumulative "so that deep interdependence entails all of the risks of shallow dependence, deep dependence and shallow interdependence" (432). As a result, the need for mitigating properties are likely to follow a similar cumulative ordering in that deep dependence for instance entail both a need for ability and reliability but also benevolence and integrity (Shapiro, Sheppard \& Cheraskin, 1992; Sheppard \& Sherman, 1998). Second, in order to establish meaning from potentially diagnostics out-of-role behavior, a trustor may first need to establish the situation as real, intersubjectively shared, and having an obdurate character (Garfinkel, 1963; Turner, 2002; Zucker, 1986). In-role behavior help establish a sense of normalcy. Without this sense of normalcy, people may be incapable to attend to and make sense of potentially trait-diagnostic role-incongruent out-of-role behavior. Inconsistency argue Rempel et al. (1985) threaten the establishment of trust because ". . . it raises the specter of a partner who is volatile and acts in unexpected, irregular ways" (p. 99).

Hypothesis 4. Perceived risk will moderate the effects of out-of-role behavior when out-of-role behavior follows after in-role behavior. People experiencing higher risk will compared to people experiencing lesser risk respond more favorably to out-of-role behavior.

\section{Study 1}

\section{Method}

Two concerns were paramount to the design. First, a primary concern was to establish the causal effects of risk and information on the formation of trust, thus motivating the choice of an experimental design. Second, we also sought to represent the type of risk people face in actual change processes. As our study deals with the effect of information in ambiguous situations, we sought to recreate some of that ambiguity. Experiments in the form of one time or repeated trust games present participants with unambiguous feedback as in the form of cooperate vs. defect. The crucial issue here however, is how people respond to ambiguous as opposed to unambiguous information, in a situation where the actual intent of the other party is open to multiple interpretations. To recreate this type of situation, we developed a set of scenarios describing both a context (the restructuring of a production plant) and two different but ultimately inconclusive episodes, 
involving a meeting with a consultant. Study 1 included participants currently working and with substantial work experience (the practitioner sample), whereas Study 2 included full-time students with little or no work experience (the student sample). The samples can be described as convenience samples. The experiments were carried out in conjunction with classes and permission with permission from the instructors. While participation was entirely voluntary, very few chose not to participate in the experiments.

\section{Sample}

The practitioner sample in Study 1 consisted of 122 individuals who were working full time at the time when the experiment was carried out. Of these, the majority were taking classes in part-time degree programs for working professionals at a Norwegian business school. 52.5\% were women, and $46.7 \%$ men (the remaining gave no information). The mean age was $38(S D=8.6)$ with the youngest 18 and the oldest 58 . Average work experience was 14.6 years $(S D=8.9)$ ranging from no experience to 35 years.

\section{Procedure and materials}

The experiment was preceded by a short introduction and instructions that were replicated on the first page of the questionnaire. The participants spent approximately 25-30 minutes completing the experiment. All manipulations and instructions were provided in the form of written texts and instructions provided in the questionnaire. Participants were introduced to a scenario of an imminent reorganization of a production company and asked to see themselves as working for a local unit of that company. The possible consequences of the reorganization for the unit they were told could go both ways - the unit could receive more resources, be downsized, or altogether disbanded. To assist the management in developing the change proposal, the management had hired a consultant with extensive experience and expertise who was expected to exert considerable influence on the final decision. The participants would work with the consultant on developing a change proposal, as representatives of their unit. Participants were randomly assigned to a high- or low-risk group. Risk was manipulated through instructions, which described the situation of the participant.

The high-risk manipulation informed the participants that they were likely to lose the job and would have difficulty finding new employment, whereas the low-risk manipulation informed the participants that they were unlikely to lose the job and would have little difficulty finding new employment.

The low-risk manipulation read:

You have been in the organization for 5 years. You do not expect your position to be substantially affected by the changes that the organization will be going through. You do however expect to spend a substantial amount of time on the project. In the case that your position should be affected or disappear, you would not expect to have any difficulties of finding a new job within the same company or possibly for another company. You look upon the prospects of a change of work as exciting. At the time you have not yet established yourself at your current work-location.

The high-risk manipulation read:

You have been in the organization for 15 years. You have spent substantial amount of time on acquiring the skills of your present job. Your position is one of the positions expected to be affected by the mentioned changes. Over time you have acquired a substantial amount of competence within your area. The need for this competence outside of the company however is limited. A change in career would at the same time mean that you have to learn a range of new skills. You have settled down with a family and built a house in the vicinity of the company. A move would thus imply considerable costs for you and your family.

A scale measuring the participant's subjective experience of the risk (subjective risk scale) and the first of three identical trust-in-the-consultant scales followed immediately after the risk manipulation. The participants were then introduced to two behavioral episodes involving the consultant. The first episode was designed to be informative about the personal traits of the consultant (the out-of-role behavior), whereas the second episode was designed to be informative about the professional role of the consultant (the in-role behavior). The last manipulation reversed the order in which the episodes (out-of-role and in-role) were introduced.

The out-of-role behavior read:

In a later meeting the consultant unexpectedly says. "I personally mean that the management of this company ought to get more involved in this process." You notice that this deviates from the official communication of the consultancy.

The in-role behavior read:

In the first meeting the consultant says the following: "We have been through an evaluation of the process so far and found that the project needs more involvement from management of the company." You are aware that the consultancy tends to do this type of processevaluations. ("In the first. ..." and "In the second." were changed depending upon the order in which the events were introduced).

The participants rated how informative the events were with respect to the role of the consultant and the personal qualities and motivations of the consultant before completing a 
trust-in-the-consultant scale. The next section then had the participants rate the importance of a series of properties associated with the consultant, for their trust in the consultant. Twelve items captured the dimensions of ability, benevolence, and integrity (Mayer \& Davis, 1999; Mayer et al., 1995). A series of control questions and a trusting propensity scale (Mayer \& Davis, 1999; Rotter, 1967) completed the experiment. The participants were finally debriefed and thanked for their participation.

The experiment applied a combination of new and established scales. The trust scale was adopted from Mayer and Davis (1999) and slightly adjusted to fit in with the specific context described in the experiment. The adjustments included changing the referents of trust (from top management to consultant), as well as adding a global item ("I trust the consultant") to capture nuances in trust possibly not captured by the other four items. Three scales for the importance of ability, benevolence, and integrity were developed from similar belief scales in Mayer and Davis (1999). Other scales, including a subjective risk scale and the scales for role- and person-diagnostic value were developed specifically for the experiment. The number of items in the importance scales (ability, benevolence, and integrity) was reduced from 6 to 4 . Seven-point Likert scales were used throughout the experiment. The wording of the scales were completely disagree or completely agree (at 1 and 7, respectively) and (for the importance scales) of very little importance and highly important (at 1 and 7 , respectively).

Cronbach's alphas for initial trust (.66), as well as for the "propensity to trust" scale (.72), were on the low side, yet consistent with previous findings (Mayer \& Davis, 1999). The integrity scale displayed low reliability (Cronbach's alphas of .54). Cronbach's alphas for variables ranged from . 54 (importance of integrity) to .92 (subjective risk).

\section{Manipulation checks}

The risk manipulations were assessed by means of a $t$-test. The difference in subjective risk (group means) between the high-risk and the low-risk manipulation groups was in the expected direction and highly significant $\left(M_{\text {high risk }}=4.13\right.$ $\left.[S D=.83], M_{\text {low risk }}=2.51[S D=.86]\right), t_{(120)}=10.58, p<.001$.

\section{Results}

\section{Hypothesis 1}

No significant relationship was observed between a general propensity to trust and initial trust in the practitioner sample, $r=.08$, ns $(n=122)$.

\section{Hypothesis 2}

The two experimental groups differed markedly in their initial toward the consultant. Participants exposed to the high condition displayed less initial trust, $M=3.25, S D=.94$, than participants in the low-risk condition, $M=3.95, S D=1.01$. This difference was highly significant, $t(120)=-4.01$, $p<.001$. The subjective risk score (based on participants subjective experience of risk in the situation) showed a strong and significant negative relationship with initial trust, $r=-.46, R_{\text {adjusted }}^{2}=.205, p<.001(n=122)$.

\section{Hypothesis 3}

Hypothesis 3 was tested through $t$ tests for differences in independent group means. Linear regressions were performed between the manipulation checks of risk to determine the size of the effect of risk on the importance measures $\left(R_{\text {adjusted }}^{2}\right)$. The first part of the hypothesis was supported (the relationship between risk and the importance of benevolence), but not the second (the relationship between risk and importance of integrity). Participants exposed to the high-risk manipulation placed greater importance on benevolence compared to participants who were exposed to the low-risk manipulation. Mean scores for the importance of benevolence in the two experimental groups were $5.05(S D=1.00)$ and 4.41 $(S D=1.46)$ for the high- and low-risk group, respectively. This difference was significant, $t_{(119)}=2.44, p<.01$ (one-tailed test). The relationship between the subjective risk score and importance of benevolence was significant in the practitioner sample, $\beta=.230, F(1,119)=6.65$ and $p<.05, R_{\text {adjusted }}^{2}=.045$.

No significant difference was found between the experimental groups in the importance attached to integrity. Mean score for the importance of integrity in the low-risk condition was 5.48 (SD .81). Mean scores in the high-risk condition was $5.52(S D .92) \cdot t(119)=.262$, ns.

\section{Hypothesis 4}

Hypothesis 2 was tested in a two-way mixed within-between analysis of variance with trust as the dependent variable. Group means are reported in Table 1. Running the analysis with three subjective risk groups revealed an interaction effect between risk and time, as suggested by Hypothesis 2 . With three subjective risk groups, there was no main effect of time, Wilk's lambda $=1.00, F(1,78)=.014, p=.907$, partial eta square $=.000$. More importantly however, a significant interaction effect was observed between subjective risk and

Table 1 Means of Participants' Trust by Subjective Risk and Time in Study 1

\begin{tabular}{|c|c|c|c|c|}
\hline & \multicolumn{2}{|l|}{ T1 } & \multicolumn{2}{|l|}{$\mathrm{T} 2$} \\
\hline & $M$ & $S D$ & $M$ & $S D$ \\
\hline High subjective risk $(n=25)$ & 3.02 & .93 & 3.45 & 1.21 \\
\hline Medium subjective risk $(n=25)$ & 3.82 & 1.19 & 3.60 & 1.24 \\
\hline Low subjective risk $(n=31)$ & 4.05 & .95 & 3.88 & 1.03 \\
\hline Total $(n=81)$ & 3.66 & 1.10 & 3.66 & 1.15 \\
\hline
\end{tabular}


time, Wilk's lambda $=.888, F(2,78)=4.93, p=.010$, partial eta square $=.112$, thus supporting Hypothesis 2 . A significant between-subjects effect was further observed for subjective risk on trust, $F(2,78)=3.612, p=.032$, partial eta square $=.085$.

\section{Discussion}

Hypothesis 1, that there would be a positive relationship between a general propensity to trust and initial trust, was not supported. Hypothesis 2, suggesting a negative direct relationship between risk and initial trust, was supported. Hypothesis 3, positing that risk would increase the importance attached to benevolence and integrity, was supported for benevolence but not integrity. Finally, Hypothesis 4, suggesting an interaction effect between subjective risk and the effect of out-of-role behavior when introduced after the in-role behavior, was supported.

\section{Study 2}

\section{Method}

\section{Sample}

The student sample in Study 2 consisted of 148 full-time students most of whom were in their second year of an undergraduate business degree program at a Norwegian business school. The majority of the students were in their early twenties. The experiment was carried out in conjunction with a mandatory course in organizational psychology held for second year students. $35.4 \%$ were women and $64.6 \%$ men. Mean age of the student sample was 22 years $(S D=1.37)$. The majority of the individuals in the student sample had no work experience. The distribution was as follows: 103 had no work experience, 27 had 1 year of work experience, 9 had 2 years, 4 had 3 years, and 4 had five or more years of work experience.

\section{Procedure and materials}

The manipulations and materials used in Study 2 were identical to the manipulations and materials used in Study 1. The participants completed the experiment in conjunction with a lecture in a large auditorium (400 seats). As for the first experiment, the experiment was preceded by a short introduction and instructions that were replicated on the first page of the questionnaire. Like in Study 1, participants in Study 2 spent approximately 25-30 minutes completing the questionnaire. All manipulations and instructions were in the form of written texts and instructions provided in the questionnaire.

\section{Manipulation checks}

As in Study 1, the risk manipulations were assessed by means of a $t$-test. The difference in subjective risk (group means) between the high-risk and the low-risk manipulation groups was in the expected direction and highly significant $\left(M_{\text {high risk }}=4.13[S D .72], M_{\text {low risk }}=2.45[S D=.71]\right), t_{(145)}=$ $14.26, p<.001$.

\section{Results}

\section{Hypothesis 1}

Unlike in the practitioner sample, there was a strong and significant relationship between a general propensity to trust and initial trust, $r=.239, R_{\text {adjusted }}^{2}=.09, p<.01(n=145)$.

\section{Hypothesis 2}

Like in the practitioner sample, there was a significant difference between the experimental groups in their initial trust toward the consultant. Again, the difference went in the hypothesized direction. Participants exposed to the high-risk manipulation displayed less initial trust, $M=3.45, S D=.97$, than the low-risk group, $M=3.91, S D=.86$. Again, this difference was highly significant, $t(144)=-3.02, p<.1$. As with the practitioner sample, the subjective risk score showed a strong (albeit somewhat weaker) and significant negative relationship with initial trust, $r=-.26, R_{\text {adjusted }}^{2}=.09, p<.001$ $(n=146)$.

\section{Hypothesis 3}

The analyses for Hypotheses 1 in Study 2 were identical to the analyses in Study 1. Hypothesis 1a and b was supported although the differences between the groups were small, barely reaching conventional levels of significance. For benevolence, the means for the high- vs. low-risk groups were $5.01(S D=1.20)$ and $4.69(S D=1.12), t_{(143)}=1.69, p<.05$ (one-tailed test). As in the practitioner sample, there was a significant relationship between risk and importance of benevolence in the student sample, $\beta=.185, F(1,143)=2.25$ and $p<.05, R_{\text {adjusted }}^{2} .028$. Again, no significant difference was found between the experimental groups in the importance attached to integrity. Mean score for the importance of integrity in the low-risk condition was 5.51 (SD .73) in the low-risk condition and $5.60(S D .71) . t(144)=-.711$, ns, in the high-risk condition.

\section{Hypothesis 4}

Hypothesis 4 received no support in Study 2. Running the analysis with three subjective risk groups revealed a significant main effect of time, Wilk's lambda $=.896, F(1,81)=9.409$, $p=.003$, partial eta square $=.104$. Group means can be found in Table 2. No support was found for Hypothesis 4 in that no significant interaction effect was observed between time and subjective risk, Wilk's lambda $=.999, F(1,81)=.056, p=.946$, 
Table 2 Means of Participants' Trust by Subjective Risk and Time in Study 2

\begin{tabular}{|c|c|c|c|c|}
\hline & \multicolumn{2}{|l|}{ T1 } & \multicolumn{2}{|l|}{$\mathrm{T} 2$} \\
\hline & $M$ & $S D$ & $M$ & $S D$ \\
\hline High subjective risk $(n=25)$ & 3.55 & 1.03 & 3.31 & 1.13 \\
\hline Medium subjective risk $(n=25)$ & 3.53 & .81 & 3.23 & .86 \\
\hline Low subjective risk $(n=31)$ & 3.86 & .91 & 3.56 & 1.06 \\
\hline Total $(n=81)$ & 3.65 & .91 & 3.36 & 1.07 \\
\hline
\end{tabular}

partial eta square $=.001$. There was no significant main effect of risk, $F(1,81)=1.213, p=.303$, partial eta square .029 .

\section{Discussion}

Hypothesis 1, positing a positive relationship between a general propensity to trust and initial trust was supported in the student sample. Hypothesis 2, suggesting a negative relationship between subjective risk and initial trust was also supported. Hypothesis 3 positing that risk would increase the importance attached to benevolence and integrity was again supported for benevolence but not integrity. Finally unlike in the practitioner sample, Hypothesis 4, suggesting an interaction effect between subjective risk and the effect of out-ofrole behavior when introduced after the in-role behavior, found no support in the student sample.

\section{General discussion}

The results thus show partial support for Hypothesis 1 of a positive relationship between a propensity to trust and initial trust: The expected relationship was not observed for the practitioner sample (in which participants had extensive work experience) but was found in the student sample (where participants had limited to none work experience). Hypothesis 2, positing a negative relationship between risk and initial trust found support with both samples.

Hypothesis 3, suggesting that risk would increase the importance attached to benevolence and integrity, was supported for benevolence in both samples. No support however was found for a similar relationship between risk and integrity in either of the samples. Hypothesis 4 suggesting an interaction effect between out-of-role behavior and perceived risk on initial trust found support in the practitioner sample but not in the student sample.

The contrasting findings for Hypothesis 1 between the two samples are interesting. In both cases, practitioners and students had very limited experience with the trustee. One possible explanation for the differences is that participants in the practitioner sample were more familiar with the type of situation described in the scenario (a reorganization and a meeting with a consultant) and experienced this situation as stronger and more well defined than students with little or no work experience. This suggests a distinction between experience with a trustee and situation strength: A trustor may have little actual experience about a trustee, yet experience a situation as strong and well defined. A trustor's familiarity with a well-defined situation enables the trustor to focus on the trustee and his or her behavior while reducing the impact of more general beliefs on initial trust.

As posited in Hypothesis 2, risk did have a significant and negative effect on initial trust. Future experiments will need to delineate the actual mechanisms through which risk reduces trust and their relative contribution to the relationship.

Hypothesis 3 suggesting a positive relationship between subjective risk and the importance of benevolence and integrity was supported for benevolence. The effects of risk on the importance of benevolence were modest and run counter to the notion of risk radically changing the nature of trust. Several factors may explain the relatively modest effect of risk on the importance ratings. First, the weak effects may be attributed to weak manipulations (Perdue \& Summers, 1986). A closer inspection reveals a more marked effect on the importance ratings of benevolence in the hypothesized direction, at more extreme values of subjective risk. Weak manipulations could mean that the studies failed to capture the range of subjective risk in which the suggested effects of risk are more noticeable (Cook \& Campbell, 1979). It is conceivable then that a more effective risk manipulation by producing more extreme levels of subjective risk would have produced a more solid support for the first hypothesis.

Counter to our hypothesis however, risk had no effect on the importance attached to integrity in either of the samples. A vulnerable trustor may see a trustee's responsiveness and benevolence as more immediately helpful than integrity in which ". . . a trustee adheres to a set of principles that the trustor finds acceptable” (Mayer et al., 1995, p. 719). Benevolence here more specifically describes a trustee's stance toward the trustor, whereas integrity describes a trustees' adherence to a general set of values that the trustor finds acceptable.

The interaction effect between risk and out-of-role behavior posited by Hypothesis 4 found support in Study 1 with the practitioner sample but not in Study 2 with the student sample. The responses to the out-of-role behavior of participants who reported medium subjective risk (negative response) differed substantially from the responses of the participants who reported the highest level of subjective risk (positive response), thus suggesting an interaction effect between risk and out-of-role behavior for very high levels of risk as opposed to more moderate levels of risk. The interaction effect observed in the practitioner sample was not replicated in Study 2 with the student sample. One possible interpretation would be that the observed interaction effect observed in the practitioner sample was a coincidence, imply- 
ing low reliability. This would indicate a need for new and more reliable experiments. However, the failure to replicate the findings in the student sample could also reflect characteristics of the participants in the student sample. Students in a business school are pursuing a study that prepares them for managerial positions. The students as a result may have difficulties adopting the position of a production worker as called for in the two studies. Instead, given their choice of education, they could be expected to adopt a "managerial" perspective on the consultant that emphasize the technical role performance of the consultant (Howard, 2000; Lopez, Rechner, \& Olson-Buchanan, 2005). Selective recruitment and informal socialization, in addition to the influence of a business school curriculum, may all influence business school students to adopt a managerial perspective on the case (Ahmeed, Chung, \& Eichenseher, 2003; Lopez et al., 2005; Thorne \& Saunders, 2002). The manipulation checks provide few guarantees that the students have adopted the position implied in the studies. On the other hand, risk did influence the importance students attached to the various dimensions of trustworthiness, in the case of ability more so than in the case of the practitioner sample. This constituted a more "subtle" manipulation check than the subjective risk scales.

Support for Hypothesis 4 in Study 1, was further substantiated by the relationships between diagnosticity scores (role and person) and change in trust. As would be expected from the arguments leading up to Hypothesis 4, we observed a positive and significant relationship between the participants' ratings of the perceived diagnosticity of out-of-role behavior and the subsequent change in trust where the outof-role-behavior was introduced after the in-role behavior. In the group of medium subjective risk, the pattern was reversed. For participants experiencing little subjective risk, we observed no significant relationship between diagnosticity of either role or person and subsequent change in either of the orders. In situations where people find that little is at stake, their motivation to allocate cognitive resources to attending to and processing social information is likely to be low (Fiske, 1993; Fiske, Lin, \& Neuberg, 1999; Fiske \& Neuberg, 1990). This suggests two possible and distinguishable effects of risk, one on effort and one effect that stems from the selective use of interpretive categories. The most notable contrast in the effect of behavior (in-role and out-ofrole) then should follow from variation in risk within the range of subjective risk, where people are motivated to pay attention to social stimuli. These however are highly tentative interpretations of some of the findings and the suggested relationships would need to be explored further in new studies. There was a significant and moderately strong relation between a general propensity to trust and initial trust in the student sample, which had little or no work experience but no corresponding relation in the practitioner sample where people were currently working and had substantial work experience. This supports the argument suggested in the literature (Gill et al., 2005; Rotter, 1967, 1971) that a general propensity to trust is likely to be influential in shaping trust in situations where people have little or no domain experience.

Other alternative variables and mechanisms that may explain the interaction effect suggested by Hypothesis 4 should be ruled out. More specifically, three alternative explanations may need to be addressed: A first alternative explanation is that participants assign specific meaning to the events and respond to the content of this assigned meaning (Dirks \& Skarlicki, 2004; Mayer et al., 1995). The participants then may interpret behavior as informative of the consultant's stand with respect to different parties and interests. People experiencing high subjective risk may interpret roleincongruent, out-of-role behavior as indicative of a consultants' antagonistic stand toward the management. In a similar vein, it is possible that the sequencing of the behavior affects the participants' substantial interpretation of the behaviors (Asch, 1946). Second, people may respond to the affective nature of the stimuli and the extent to which the affective content of these stimuli matches their own affective state in that situation (Byrne, 1971; Byrne, Clore, \& Smeaton, 1986; Pinel et al., 2004). Thus, a consultant indicating frustration by deviating from professional norms (out-of-role-behavior) may better match the affective state of people experiencing high subjective risk.

Third, risk may affect people's willingness to accept risk with a trustee. People exposed to risk in a situation may be more inclined to accept and value risky departures from expected behavior. Because people exposed to risk may have discounted the prospects associated with the outcomes, they may see themselves as having less to loose and more to gain by what they see as departures from the consultant's normal script of behavior. As a result, they may respond more favorably to such departures than less exposed, more conservative trustors and employees.

The effect of risk on people's decision making can be broken down in two parts: First, the situation may look different depending on the amount of risk facing a trustor. Valuing "risky" out-of-role behavior may be rational for vulnerable participants as the status quo, represented by a reliable in-role performance, in itself represents a considerable threat. Vulnerable individuals stand to lose more from the status quo (in-role behavior) and less from deviations from status quo (as represented by role-incongruent out-of-role-behavior). Second, the manipulation may lead people to frame the situation in terms of losses rather than wins. Prospect theory (Kahneman \& Tversky, 1979) suggests that framing an outcome in terms of losses increases people's willingness to take risk. People experiencing higher subjective risk in their situation then should be more inclined to accept "risky" departures from the role expectations associated with the 
trustee. Yet, as previously noted, we find a negative relation between risk and initial trust, which runs counter to the notion of risk leading people to accept more risk in their interactions with the consultant.

A fourth, possible alternative explanation, is that people possess cognitive schemas that describe how relationships and intimacy evolves or should evolve in different forms and stages of a relationship (Fehr, 2004; Miller \& Read, 1991; Rule, Bisanz, \& Kohn, 1985; Schank \& Abelson, 1977). New encounters may activate schemas, which proceed to guide further processing of information. People respond to the conformance or possible deviations from these schemas. This last explanation resembles the mechanisms suggested here where trust is seen as influenced by the congruence or incongruence between an activated interpretive schema and social stimuli (behavior). Where the explanations diverge are in the notion of schemas as encompassing not only single events or behaviors but even the relationship and natural progression of such events. Thus, Fehr (2004) shows through a series of studies, how intimacy expectations influence people's interpretation of relationship events in same-sex friendships. Ruling out the effects of cognitive schema on information processing is difficult. At the same time, the effects of schemas and of spontaneous responses to stimuli on trust may be thought of as coexisting and do not necessarily constitute mutually exclusive explanations.

\section{Limitations and directions for further research}

The two studies have limitations that include weak manipulations, mono-operations of behavior as an independent variable, and a lack of tests of mediating mechanisms. The effects of the manipulations on trust were weak. No significant overall effect of time on trust was found in either of the studies (5\%). The lack of an overall significant effect of time on trust may reflect the reality of the phenomenon studied. Thus, trust may be resilient to change in the short run. But weak effects may also reflect properties of the manipulation.

In the studies, in-role and out-of-role-behavior were each represented with a single exemplar. The mono-operation of independent variables according to Cook and Campbell (1979) lowers construct validity because single operations are likely to underrepresent constructs, as well as contain irrelevancies that could influence the dependent variable. However, increasing the number of treatments (by including different sets of behavior) is likely to lead to either very large samples or small cell sizes (Cook \& Campbell, 1979).

The two studies test the relationship between variables at the extreme ends of a causal chain. Mediating relations and mechanisms described in the development of the hypotheses were not tested. This leaves open questions with respect to the causal interpretation of the findings reported here. The ability of the risk to influence the form and mode of trust development constitute a rationale for the model. Thus, testing for the effect of risk on trust constitutes a necessary but not sufficient first stage in a more complete test of the model. Some findings however including the relationship between the diagnosticity measures and change in trust are consistent with the mediating mechanisms described in the development of Hypothesis 2.

The studies also raise the more fundamental question of whether these really study trust at all. An argument could be made that the trust scores merely reflect people's likes or dislikes of the events reflected in the ratings (DuCharme, 1970). The studies described here then can be seen as forcing people to evaluate these events in the form of trust, whereas the same reactions could have been labeled with other constructs (Orne, 1962; Ray, 1984; Winkler, Kanouse, \& Ware, 1982). Speaking of trust in relationship, to our findings however, we argue, gives meaning for several reasons: First, the trust scale consists of several items and people do differentiate between these items suggesting that people are not mindlessly applying a general evaluative response to the nearest scale at hand. Second, people have been shown to form judgments on the basis of very brief sections of information (Borkenau, Mauer, Riemann, Spinath \& Angleitner, 2004; Lutz \& Lakey, 2001).Third, trust does constitute an important element in people's appraisal of other people in the type of situations described. The role of trust in people's appraisal and evaluation of other people comes up in a series of empirical studies of work relationships (Burt \& Knez, 1996; Gabarro, 1990). Studies of situations involving conflicting interests suggest that trust constitute an immediate and salient issue in this type of interactions (Kramer, 1994; Rusbult \& Van Lange, 2003).

Finally, convenience samples like the ones used for these experiments raise questions about whether the findings can be generalized beyond the actual samples used. Students are likely to differ from the rest on the population on a series of dimensions that may include work experience (low), age (young), scholastic aptitude (high).Still; we do not consider this a major disadvantage here for several reasons: First, our primary emphasis here is on internal validity, not external validity. Second, the samples, while drawn from a population of students, differed in some important ways. Thus, one sample consisted of part-time students that had considerable work experience and who were currently working. The other sample consisted of a more traditional student sample; fulltime students with little or no work experience. This provides us with some insight into the effect of work experience on people's reactions to the manipulations: a major concern in the development of the experiments. Finally, selection was in terms of classes, not individuals; very few students opted not to participate in the experiment; hence, the problem of selfselection was a minor concern. 
New studies should seek to improve our understanding of the relations as well as rule out alternative explanations. First, the weak effects of the manipulations in the two studies suggest that new studies should be designed to elicit stronger responses. Stronger stimuli could imply substituting written manipulations with other stimuli that could include film, photos, or role plays. Merely strengthening the content of the written instruction may be counterproductive. If negative outcomes become expected, participants may see little reason to engage in processing of information about the trustee and may instead resort to stereotyping and derogating the trustee (Dépret \& Fiske, 1999; Insko, Schopler, Hoyle, Dardis, \& Graetz, 1990). Instructions involving no risk, on the other hand, may cause participants to lose interest in the experiment (Fiske, 1993). The latter may result in responses that reflect highly general schemas as opposed to experimental manipulations (Fiske \& Neuberg, 1990).

Second; extensions and replications of the studies should attempt to strengthen and validate the causal argument behind the hypotheses. First, future studies may be designed to test mediating mechanisms implied but not explicitly tested in the current design, thus developing a causal chain of events to substantiate the model. A series of mechanisms are implied but not tested in the two studies. Thus, risk is suggested to influence people's construal of the situation in specific ways. Such implied effects could be tested by asking participants to rate the situation on dimensions that may include dependence or covariance of interests (Rusbult \& Van Lange, 2003). The model further specifies that risk will lead to the activation of specific information goals and interpretive categories. The relation between risk and selective schema activation could be tested using implicit measures of schema activation, including measures of response latency (Fazio \& Olson, 2003). Finally, the relation between schema congruence and trust could be tested through experiments that manipulate and measure congruence, fluency of processing, subjective control, and trust. Such experiments may include a common set of manipulations while testing effects on different dependent variables (Spencer, Zanna, \& Fong, 2005).

\section{Implications for practice}

The suggested interpretation of the findings that people respond to their experience of information processing and the match or appropriateness of social stimuli to informational goals carries a series of practical implications: People depend on other people's trust in a wide variety of settings. People's initial impressions of consultants, salespeople, or coworkers frequently influence the subsequent trajectory of these relationships. Whereas previous contributions on initial trust have highlighted the importance of initial categorizations, or stereotypes (McKnight et al., 1998), here we suggest that initial trust may reflect the extent to which the behavior and signals people convey in interaction match the informational goals and requirements the trustor have in a particular situation. Our study is consistent with previous studies, which show how affective priming may influence the formation of initial trust (Dunn \& Schweitzer, 2005) but differ in that the affective effects are seen as originating from people's experience of information processing. As this situation changes and people become more or less exposed to risk, these goals and informational requirements are likely to change, in turn affecting the effect of behavior on trust. This suggests that people in ambiguous situations may benefit from adapting their behavior to better fit the informational goals of the trustor-for instance, a more trait-diagnostic "personal style" of interaction may be better suited for a trustor exposed to high risk, whereas a more constrained, role-confined performance may be better suited for a trustor exposed to little risk.

\section{References}

Ahmeed, M. M., Chung, K. Y., \& Eichenseher, J. W. (2003). Business students' perception of ethics and moral judgment: A cross cultural study. Journal of Business Ethics, 43, 89-102.

Ajzen, I. (1971). Attribution of dispositions to an actor: Effects of perceived decision freedom and behavioral utilities. Journal of Personality and Social Psychology, 18, 144-156.

Asch, S. E. (1946). Forming impressions of personality. Journal of Abnormal and Social Psychology, 41, 1230-1240.
Barber, B. (1983). The logic and limits of trust. New Brunswick, NJ: Rutgers University Press.

Borkenau, P., Mauer, N., Riemann, R., Spinath, F. M., \& Angleitner, A. (2004). Thin slices of behavior as cues of personality and intelligence. Journal of Personality and Social Psychology, 86, 599-614.

Burt, R. S., \& Knez, M. (1996). Trust and third-party gossip. In R. M. Kramer \& T. R. Tyler (Eds.), Trust in organizations: Frontiers of theory and research (pp. 68-89). Thousand Oaks, CA: Sage.

Byrne, D. (1971). The attraction paradigm. New York: Academic Press.
Byrne, D., Clore, G. L., \& Smeaton, G. (1986). The attraction Hypothesis: Do similar attitudes affect anything. Journal of Personality and Social Psychology, 51, $1167-1170$.

Cook, T. D., \& Campbell, D. T. (1979). Quasi-experimentation: Design \& analysis issues for field settings. Boston, MA: Houghton Mifflin.

Das, T. K., \& Teng, B. S. (2004). The riskbased view of trust: A conceptual framework. Journal of Business and Psychology, 19, 85-116.

Davis, F. D., \& Kotteman, J. E. (1994). User perceptions of decision support 
effectiveness: Two production planning experiments. Decision Sciences, 25, 57-77.

Dépret, E., \& Fiske, S. T. (1999). Perceiving the powerful: Intriguing individuals versus threatening groups. Journal of Experimental Social Psychology, 35, 461480.

Dirks, K. T., \& Skarlicki, D. P. (2004). Trust in leaders: Existing research and emerging issues. In R. M. Kramer \& K. S. Cook (Eds.), Trust and distrust in organizations: Dilemmas and approaches (pp. 21-40). New York: Russell Sage Foundation.

DuCharme, W. M. (1970). Response bias explanation of conservative human inference. Journal of Experimental Psychology, 85, 66-74.

Dunn, J. R., \& Schweitzer, M. E. (2005). Feeling and believing: The influence of emotion on trust. Journal of Personality and Social Psychology, 88, 736-748.

Erber, R., \& Fiske, S. T. (1984). Outcome dependency and attention to inconsistent information. Journal of Personality and Social Psychology, 81, 709-726.

Erikson, E. H. (1968). Identity: Youth and crisis. New York: Norton.

Falkenberg, J., Stensaker, I. G., Meyer, C. B., \& Haueng, A. C. (2005). When change becomes excessive. Research in Organizational Change and Development, 15, 31-62.

Fazio, R. H., \& Olson, M. A. (2003). Implicit measures in social cognition research: Their meaning and use. Annual Review of Psychology, 54, 297-327.

Fehr, B. (2004). Intimacy expectations in same-sex friendships: A prototype interaction pattern model. Journal of Personality and Social Psychology, 86, 265-284.

Ferguson, M. J., \& Bargh, J. A. (2004). Liking is for doing: The effects of goal pursuit on automatic evaluation. Journal of Personality and Social Psychology, 87, 557-572.

Fiske, A. P. (1992). The 4 elementary forms of sociality: Framework for a unified theory of Social relations. Psychological Review, 99, 689-723.

Fiske, S. T. (1993). Controlling other people: The impact of power on stereotyping. The American Psychologist, 48, 621-628.

Fiske, S. T., Lin, M., \& Neuberg, S. L. (1999). The continuum model: Ten years later. In
S. Chaiken \& Y. Trope (Eds.), Dualprocess theories in social psychology (pp. 231-254). New York: Guilford Press.

Fiske, S. T., \& Neuberg, S. L. (1990). A continuum of impression formation, from category based to individuating processes: Influences of information and motivation on attention and interpretation. Advances in Experimental Social Psychology, 23, 1-74.

Gabarro, J. J. (1990). The development of working relationships. In J. Gallagher (Ed.), Intellectual teamwork: Social and technological foundations of cooperative work (pp. 79-110). Hillsdale, NJ: Erlbaum.

Gambetta, D. (Ed.). (1988). Trust: Making or breaking cooperative relations. Oxford, England: Blackwell.

Garfinkel, H. (1963). A conception of, and experiments with, "trust" as a condition of stable concerted actions. In O. J. Harvary (Ed.), Motivation and social interaction (pp. 187-238). New York: Ronald Press.

Giddens, A. (1991). Modernity and selfidentity: Self and society in the late modern age. Stanford, CA: Stanford University Press.

Gilbert, D. T. (1998). "Ordinary” personology. In D. T. Gilbert, S. T. Fiske, \& G. Lindzey (Eds.), The handbook of social psychology (4th ed., pp. 89-150). New York: McGraw Hill.

Gill, H., Boies, K., Finegan, J. E., \& McNally, J. (2005). Antecedents of trust: Establishing a boundary condition for the relation between propensity to trust and intention to trust. Journal of Business and Psychology, 19, 287-302.

Gollwitzer, P. M., Heckhausen, H., \& Steller, B. (1990). Deliberative and implemental mind-Sets: Cognitive tuning toward congruous thoughts and information. Journal of Personality and Social Psychology, 59, 1119-1127.

Guiot, J. (1977). Attribution and identity construction: Some comments. American Sociological Review, 42, 692-704.

Higgins, E. T. (1997). Beyond pleasure and pain. The American Psychologist, 52, 1280-1300.

Higgins, E. T., Idson, L. C., Freitas, A. L., Spiegel, S., \& Molden, D. C. (2003). Transfer of value from fit. Journal of Per- sonality and Social Psychology, 84, 11401153.

Holmes, J. G. (2002). Interpersonal expectations as the building blocks of social cognition: An interdependence theory perspective. Personal Relationships, 9, $1-26$.

Howard, J. W. (2000). Social psychology of identities. Annual Review of Sociology, 26, 367-393.

Insko, C. A., Schopler, J., Hoyle, R. H., Dardis, G. J., \& Graetz, K. A. (1990). Individual group discontinuity as a function of fear and greed. Journal of Personality and Social Psychology, 58, 68-79.

Johnson-George, C., \& Swap, W. C. (1982). Measurement of specific interpersonal trust: Construction and validation of a scale to assess trust in a specific other. Journal of Personality and Social Psychology, 43, 1306-1317.

Jones, E. E., Davis, K. E., \& Gergen, K. J. (1961). Role playing variations and their informational value for person perception. Journal of Abnormal and Social Psychology, 63, 302-310.

Kahneman, D., \& Tversky, A. (1979). Prospect theory: Analysis of decision under risk. Econometrica, 47, 263-291.

Kelley, H. H., Holmes, J. G., Kerr, N. L., Reis, H. T., Rusbult, C. E., \& Van Lange, P. A. M. (2002). An atlas of interpersonal situations. New York: Cambridge University Press.

Kelley, H. H., \& Thibaut, J. W. (1978). Interpersonal relations. New York: Wiley.

Kramer, R. M. (1994). The sinister attribution error: Paranoid cognition and collective distrust in organizations. Motivation and Emotion, 18, 199-230.

Kramer, R. M. (1996). Divergent realities and convergent disappointments in the hierarchic relation: Trust and the intuitive auditor at work. In R. M. Kramer \& T. R. Tyler (Eds.), Trust in organizations: Frontiers of theory and research (pp. 216245). Thousand Oaks, CA: Sage.

Kramer, R. M. (1999). Trust and distrust in organizations: Emerging perspectives, enduring questions. Annual Review of Psychology, 50, 569-598.

Lane, C. L. (1998). Introduction: Theories and Issues in the Study of Trust. In C. L. Lane \& R. Bachmann (Eds.), Trust within and between organizations: Conceptual 
issues and empirical applications (pp. 1-30). Oxford, England: Oxford University Press.

Lewicki, R., \& Bunker, B. B. (1996). Developing and maintaining trust in work relationships. In R. M. Kramer \& T. R. Tyler (Eds.), Trust in organizations: Frontiers of theory and research (pp. 114-139). Thousand Oaks, CA: Sage.

Lopez, Y. P., Rechner, P. L., \& OlsonBuchanan, J. B. (2005). Shaping ethical perceptions: An empirical assessment of the influence of business education, culture and demographic factors. Journal of Business Ethics, 60, 341-358.

Luhmann, N. (1979). Trust and power. Chichester, England: Wiley.

Lutz, C. J., \& Lakey, B. (2001). How people make support judgments: Individual differences in the traits used to infer supportiveness in others. Journal of Personality and Social Psychology, 81, 10701079.

MacLeod, C., \& Mathews, A. (1988). Anxiety and the allocation of attention to threat. Quarterly Journal of Experimental Psychology, 40, 653-670.

Mayer, R. C., \& Davis, J. H. (1999). The effect of the performance appraisal system on trust for management: A field quasi-experiment. The Journal of Applied Psychology, 84, 123-136.

Mayer, R. C., Davis, J. H., \& Schoorman, F. D. (1995). An integrative model of organizational trust. Academy of Management Review, 20, 709-734.

McAllister, D. J. (1995). Affect-based and cognition-based trust as foundations for interpersonal cooperation in organizations. Academy of Management Journal, 38, 24-59.

McKenna, C. D. (2006). The world's newest profession: Management consulting in the twentieth century. New York: Cambridge University Press.

McKnight, D. H., \& Chervany, N. L. (2006). Reflections on an initial trust-building model. In R. Bachmann \& A. Zaheer (Eds.), Handbook of trust research (pp. 29-51). Cheltenham, UK: Edward Elgar.

McKnight, D. H., Cummings, L. L., \& Chervany, N. L. (1998). Initial trust formation in new organizational relationships. Academy of Management Review, 23, 473-490.
Meyerson, D., Weick, K., \& Kramer, R. M. (1996). Swift trust and temporary groups. In R. M. Kramer \& T. R. Tyler (Eds.), Trust in organizations: Frontiers of theory and research (pp. 166-195). Thousand Oaks, CA: Sage.

Miller, L. C., \& Read, S. J. (1991). On the coherence of mental models of persons and relationships: A knowledge structure approach. In G. J. O. Fletcher \& F. D. Fincham (Eds.), Cognition in close relationships (pp. 69-100). Hillsdale, NJ: Erlbaum.

Mischel, W. (1977). The interaction of person and situation. In D. Magnusson \& N. S. Endler (Eds.), Personality at the crossroads: Current issues in interactional psychology (pp. 333-352). Hillsdale, NJ: Erlbaum.

Neuberg, S. L., \& Fiske, S. T. (1987). Motivational influences on impressionformation-Outcome dependency, accuracy-driven attention, and individuating processes. Journal of Personality and Social Psychology, 53, 431-444.

Orbell, J., \& Dawes, R. M. (1991). A cognitive miser theory of co-operators advantage. The American Political Science Review, 85, 515-528.

Orne, M. T. (1962). On the socialpsychology of the psychological experiment-With particular reference to demand characteristics and their implications. The American Psychologist, 17,776-783.

Ostrom, E. (2003). Toward a behavioral theory linking, trust, reciprocity, and reputation. In E. Ostrom \& J. Walker (Eds.), Trust and reciprocity: Interdisciplinary lessons from experimental research (pp. 19-79). New York: Russell Sage Foundation.

Perdue, B. C., \& Summers, J. O. (1986). Checking the success of manipulations in marketing experiments. Journal of Marketing Research, 23, 317-326.

Pinel, E. C., Long, A., Landau, M., \& Pyszczynski, T. (2004). I-sharing and the problem of existential isolation. In J. Greenberg, S. Koole, \& T. Pyszczynski (Eds.), Handbook of experimental existential psychology (pp. 352-368). New York: Guilford Press.

Ray, J. J. (1984). Reinventing the wheel: Winkler, Kanouse and Ware on acquies- cent response set. The Journal of Applied Psychology, 69, 353-355.

Rempel, J. K., Holmes, J. G., \& Zanna, M. P. (1985). Trust in close relationships. Journal of Personality and Social Psychology, 49, 95-112.

Rotter, J. B. (1967). A new scale for the measurement of interpersonal trust. Journal of Personality, 35, 651-665.

Rotter, J. B. (1971). Generalized expectancies for interpersonal trust. The American Psychologist, 26, 443-452.

Rule, B. G., Bisanz, G. L., \& Kohn, M. (1985). Anatomy of a persuasion schemaTargets, goals and strategies. Journal of Personality and Social Psychology, 48, 1127-1140.

Rusbult, C. E., \& Van Lange, P. A. M. (2003). Interdependence, interaction and relationships. Annual Review of Psychology, 54, 351-375.

Saunders, C. S., \& Ahuja, M. K. (2006). Are all distributed teams the same? Differentiating between temporary and ongoing distributed teams. Small Group Research, 27, 662-700.

Schank, R. C., \& Abelson, R. P. (1977). Scripts, plans, goals, and understanding: An inquiry into human knowledge structures. Hillsdale, NJ: Erlbaum.

Selart, M. (2010). A leadership perspective on decision making. Oslo, Norway: Cappelen.

Shapiro, D. L., Sheppard, B. H., \& Cheraskin, L. (1992). Business on a handshake. Negotiation Journal, 8, 365-377.

Sheppard, B. H., \& Sherman, D. M. (1998). The grammars of trust: A model and general implications. Academy of Management Review, 23, 422-437.

Sitkin, B., \& Pablo, A. L. (1992). Reconceptualizing the determinants of risk behavior. Academy of Management Review, 17, 9-38.

Spencer, S. J., Zanna, M. P., \& Fong, G. T. (2005). Establishing a causal chain: Why experiments are often more effective than mediational analyses in examining psychological processes. Journal of Personality and Social Psychology, 89, 845851.

Taylor, S. E., \& Gollwitzer, P. M. (1995). Effects of mindsets on positive illusions. Journal of Personality and Social Psychology, 69, 213-226. 
Thorne, L., \& Saunders, S. B. (2002). The socio-cultural embeddedness of individuals' ethical reasoning in organizations (cross-cultural ethics). Journal of Business Ethics, 35, 1-14.

Turner, J. H. (2002). Face to face. Toward a sociological theory of interpersonal behavior. Stanford, CA: Stanford University Press.

Vlaar, P. W. L., Van den Bosch, F. A. J., \& Volberda, H. W. (2007). On the evolution of trust, distrust and formal coordination and control in inter-organizational relationships: Toward an integrative framework. Group and Organization Management, 32, 407-429.

Weber, J. M., Malhotra, D., \& Murnighan, J. K. (2005). Normal acts of irrational trust: Motivated attributions and the trust development process. Research in Organizational Behavior, 26, 71101.

Williams, M. (2001). In whom we trust: Group membership as an affective context for trust development. Academy of Management Review, 26, 377396.

Winkler, J. D., Kanouse, D. E., \& Ware, J. E. (1982). Controlling for acquiescence response set in scale development. The Journal of Applied Psychology, 67, 555561.

Zucker, L. G. (1986). Production of trust: Institutional sources of economic structure, 1840-1920. Research in Organizational Behavior, 8, 53-111. 